\title{
Fatal ischaemic brain oedema after early thrombolysis with tissue plasminogen activator in acute stroke
}

\author{
P J Koudstaal, J Stibbe, M Vermeulen
}

\begin{abstract}
Two patients with acute major, disabling cerebral infarction with presumed middle cerebral artery occlusion were treated with the clot specific thrombolytic agent tissue plasminogen activator roughly three and a half hours after the onset of symptoms. Both patients had a normal computed tomography (CT) scan before treatment. No appreciable systemic bleeding complications occurred, apart from bruising. One patient had bleeding into the subarachnoid space from a microscopic angioma, which was found at necropsy. Haematological monitoring of the two patients showed pronounced fibrinogenolysis and $\alpha_{2}$ antiplasmin consumption in one. One patient showed transient improvement during the infusion. In both cases extensive infarction, partly haemorrhagic in one, with massive concomitant oedema was found on repeated CT. Both patients deteriorated and eventually died as a consequence of transtentorial herniation. In the one patient who came to necropsy a moderate, probably pre-existing smooth stenosis of the ipsilateral carotid artery was found, all cerebral vessels being patent.

It is concluded that thrombolytic treatment with a clot specific agent such as tissue plasminogen activator started three to four hours after a major ischaemic stroke may be hazardous, not because of haemorrhagic transformation of the original ischaemia but because early reperfusion may promote massive, potentially fatal cerebral oedema.
\end{abstract}

\section{Introduction}

As most ischaemic strokes are caused by thromboembolism, ${ }^{12}$ thrombolysis may be a potentially important treatment. Clinical trials with fibrinolysin, ${ }^{3}$ plasmin ${ }^{4}$ streptokinase ${ }^{5}$ and urokinase ${ }^{6}$ showed that this treatment was associated with haemorrhagic transformation of the original cerebral infarct. These early trials have been criticised, ${ }^{78}$ mainly because in all of them treatment was started at least eight hours after the onset of symptoms. By that time permeability changes in the blood-brain barrier have occurred, which may result in mild to moderate haemorrhagic infarcts once the blood flow is restored. ${ }^{9}$ Recently a series of patients with stroke were treated with streptokinase intraarterially within six hours, leading to effective recanalisation in $90 \%$ of patients (proved by angiography) and clinical improvement in $60 \%{ }^{10}$

An important drawback with the fibrinolytic agents listed above is the activation of plasminogen outside the clot, which may induce a lytic state. Tissue type plasminogen activator is more clot specific in that it promotes the conversion of plasminogen to plasmin only when bound to fibrin in a thrombus. ${ }^{112}$ This treatment proved highly effective in patients with acute myocardial infarction. ${ }^{13-15}$
The application of tissue plasminogen activator in acute cerebral infarction is limited to studies in animals, which showed a significant reduction in death and severity of neurological dysfunction without any concomitant bleeding complication,,$^{16-18}$ and to a single, favourable report in a patient with vertebrobasilar occlusion. ${ }^{19}$

The aim of this clinical study was to investigate whether tissue plasminogen activator can be given safely to patients with acute cerebral infarction of less than four hours' duration.

\section{Patients, methods, and results}

The two patients described below were the first of a series of 10 planned for a pilot study of thrombolysis with tissue plasminogen activator in acute stroke which was begun at this hospital in November 1987.

\section{ELIGIBILITY FOR STUDY}

Criteria for entry to the study were acute symptoms of ischaemia in the carotid territory lasting more than one hour and less than four hours; no spontaneous improvement; severity of symptoms such that the patient was unable to walk or stand unaided, use the affected arm, or give name and address; age under 75; and a normal computed tomography (CT) scan. Reasons for exclusion were impaired consciousness; any concomitant disabling disorder; acute cerebral symptoms from causes other than artery to artery embolism, such as migraine, anaemia, thrombocytosis, hypoglycaemia, and an obvious cardioembolic source on admission; and contraindications to tissue plasminogen activator, such as a bleeding disorder, recent surgery or biopsy, hepatic or renal disease, chronic, poorly controlled hypertension (systolic blood pressure $>220 \mathrm{~mm} \mathrm{Hg}$ and diastolic pressure $>120 \mathrm{~mm} \mathrm{Hg}$ for at least one hour despite antihypertensive treatment, and use of anticoagulants.

\section{INVESTIGATIONS}

Angiography was not performed. CT scans were made on admission and repeated after one, three, and seven days. Laboratory measurements were haemoglobin concentration, packed cell volume, platelet count, serum urea and creatinine concentrations, and hepatic enzyme activities. Parameters of coagulation and fibrinolysis measured were fibrinogen concentration (by the method of Clauss ${ }^{20}$ ), fibrin-fibrinogen degradation products (latex test; Boehringer-Mannheim, Almere, The Netherlands), plasminogen and $\alpha_{2}$ antiplasmin activities (both by amidolytic assays), thrombin time (sensitive for both fibrin-fibrinogen degradation products and heparin), reptilase time (prolonged by fibrin-fibrinogen degradation products but unaffected by heparin), and heparin neutralisation by protamine using the thrombin time. 


\begin{tabular}{|c|c|c|c|c|c|c|c|c|c|c|c|}
\hline & \multirow[b]{2}{*}{$\begin{array}{c}\text { Normal } \\
\text { range }\end{array}$} & \multicolumn{5}{|c|}{ Case 1} & \multicolumn{5}{|c|}{ Case 2} \\
\hline & & $\begin{array}{c}\text { Before } \\
\text { treatment }\end{array}$ & $\begin{array}{c}\text { End of } \\
\text { treatment }\end{array}$ & $\begin{array}{c}\text { After } \\
2 \mathrm{~h}\end{array}$ & $\begin{array}{c}\text { After } \\
6 \mathrm{~h}\end{array}$ & $\begin{array}{c}\text { After } \\
24 \mathrm{~h}\end{array}$ & $\begin{array}{c}\text { Before } \\
\text { treatment }\end{array}$ & $\begin{array}{c}\text { End of } \\
\text { treatment }\end{array}$ & $\begin{array}{l}\text { After } \\
2 \mathrm{~h}\end{array}$ & $\begin{array}{l}\text { After } \\
8 \mathrm{~h}\end{array}$ & $\begin{array}{c}\text { After } \\
24 \mathrm{~h}\end{array}$ \\
\hline Fibrinogen $(\mathrm{g} / \mathrm{l})$ & $1 \cdot 8-3 \cdot 6$ & $2 \cdot 4$ & $<0 \cdot 1$ & $0 \cdot 3$ & $0 \cdot 4$ & $1 \cdot 0$ & $3 \cdot 7$ & 0.8 & $1 \cdot 0$ & 0.8 & $1 \cdot 3$ \\
\hline Fibrin degradation products (mg/l) & $<10$ & $<10$ & 100 & 60 & 80 & 70 & $<10$ & 160 & $>100$ & 60 & - \\
\hline Plasminogen $(\mathrm{U} / \mathrm{ml})$ & $0 \cdot 85-1 \cdot 20$ & 0.80 & 0.31 & $0 \cdot 40$ & 0.39 & 0.57 & $1 \cdot 12$ & 0.46 & 0.52 & 0.60 & 0.70 \\
\hline$\alpha_{2}$ Antiplasmin (U/ml) & $0 \cdot 85-1 \cdot 20$ & 0.82 & ND & 0.07 & $0 \cdot 21$ & 0.44 & 1.02 & 0.07 & $0 \cdot 12$ & $0 \cdot 36$ & 0.69 \\
\hline Reptilase time (s) & $20-27$ & 24 & 52 & 50 & 49 & 23 & 31 & 49 & 46 & 44 & 31 \\
\hline Thrombin time (s) & $9-13$ & $>60^{\star \star}$ & 28 & 25 & 28 & 17 & 13 & $>60^{\star}$ & 23 & 22 & 49* \\
\hline
\end{tabular}

$\mathrm{ND}=$ Not detectable.

^Contamination with heparin from indwelling catheter.

\section{TREATMENT}

Treatment with tissue plasminogen activator (Actilyse; Boehringer-Ingelheim) started with a bolus injection of $10 \mathrm{mg}$, followed by continuous infusion of $50 \mathrm{mg}$ for the first hour and $40 \mathrm{mg}$ for the second and third hours (total $100 \mathrm{mg}$ ).

\section{PATIENTS ACCEPTED INTO STUDY}

From 1 November 1987 till 1 April 1988, 59 patients with an acute major ischaemic stroke were admitted to our department. Reasons for exclusion were: age over 75 (32 patients); admission more than four hours after onset of symptoms (16); neurological deficit too mild (one) or improving spontaneously (four); congestive heart failure and atrial fibrillation (two); and use of anticoagulants (two). Seven of the non-eligible patients died in hospital. Causes of death were pneumonia in two patients, urosepsis in one, and coning in four.

During the first five months of the study only two patients were eligible for treatment.

Case 1

The first patient was a 63 year old left handed man, whose history included a nephrectomy in 1950, myocardial infarction in 1977, and psoriasis and hypertension, for which he was taking propranolol. Stroke was manifested by a sudden onset of paralysis of the left arm and leg and inability to speak. On admission one and a half hours later he was alert, had a forced deviation of head and eyes to the right, and was unable to speak but obeyed simple commands with his right arm. There was a complete leftsided hemiplegia and Babinski's sign was present on the left. Blood pressure was $170 / 100 \mathrm{~mm} \mathrm{Hg}$. Laboratory results, chest $x$ ray picture, and an electrocardiogram were normal, as was a CT scan of the brain.

Three and a half hours after the onset of symptoms the patient began treatment with tissue plasminogen activator. One hour later the forced deviation of head and eyes disappeared and the patient could give his name and address. He appeared well oriented and answered simple questions intelligibly. There was minor bruising at the injection sites. A few hours after the infusion, however, the patient became mute again and vomited twice. Next morning he appeared drowsy and did not obey commands. CT was repeated and disclosed a massive infarction with concomitant oedema of the right hemisphere affecting both the anterior and middle cerebral arteries. The infarct was partially haemorrhagic with evidence of bleeding into the subarachnoid space, but there was no substantial intracerebral haemorrhage. Monitoring of haemostasis showed pronounced systemic fibrinolysis and $\alpha_{2}$ antiplasmin consumption (table). The patient continued to deteriorate. A third CT scan showed increased ischaemic cerebral oedema with consequent herniation of the temporal lobe but no increase of the haemorrhagic components of the infarct. The patient died two and a half days after the onset of the stroke.

At necropsy a tight, smooth stenosis of the right internal carotid artery was found. All cerebral vessels were patent and there was no evidence of thrombus formation either within the brain or in the heart. Microscopic examination showed an angioma on the right parietal brain convexity which had probably been the cause of the subarachnoid bleeding.

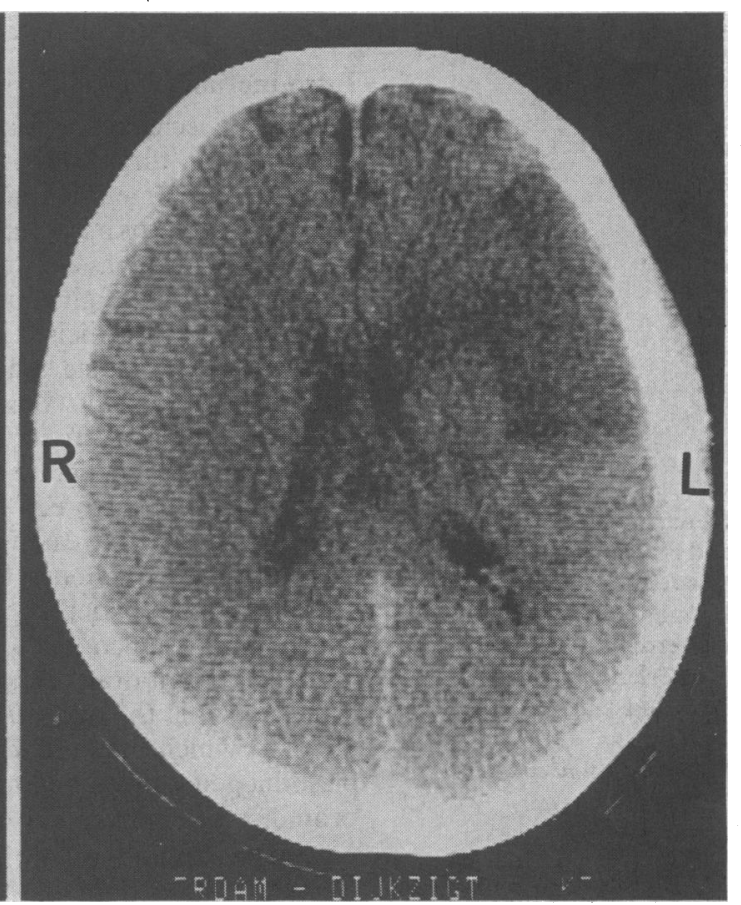

FIG 1-Case 2. CT appearances of brain on day 3 

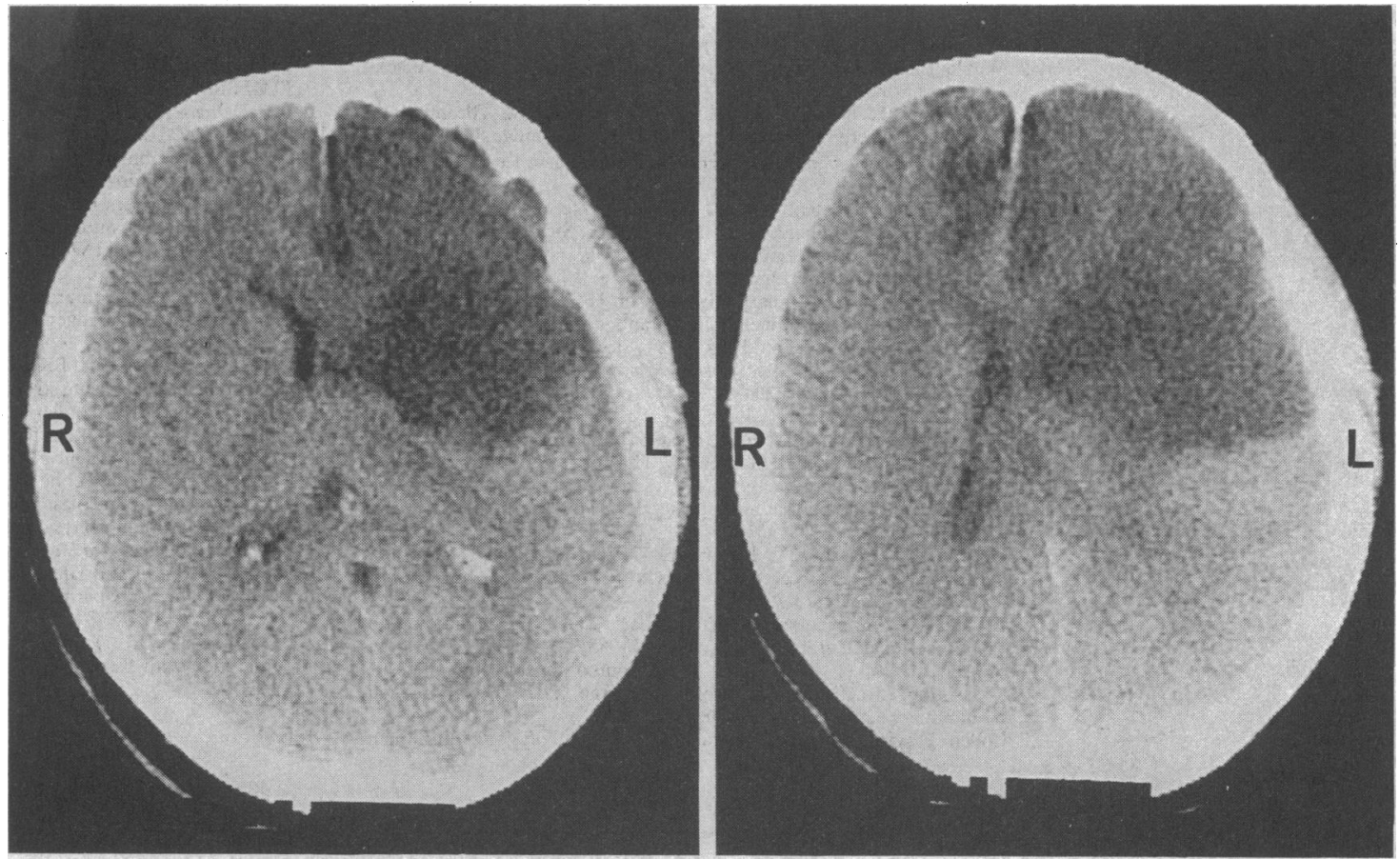

FIT 2-Case 2. CT appearances of brain on day 5 .

\section{Case 2}

Our second patient was a 59 year old man with a history of intermittent claudication. He was receiving naproxen, which he used irregularly. At about $530 \mathrm{pm}$ he suddenly fell down while taking a shower. He remained conscious but unable to speak or move his right arm. On admission he was alert, had a forced deviation of the eyes to the left, and could not speak but obeyed simple commands. He had a right hemianopia and paralysis of the right arm and face. Plantar reflexes were normal on both sides. Blood pressure was $150 / 100 \mathrm{~mm} \mathrm{Hg}$. Laboratory findings, chest $x$ ray appearances, an electrocardiogram, and a CT scan were all normal.

Three hours 20 minutes after the onset of symptoms the patient began treatment with tissue plasminogen activator. By the next day his condition had not altered. On the second day he developed a paresis of the left leg. The CT scan was repeated on the third day and disclosed a subtotal non-haemorrhagic infarction of the left middle cerebral artery and an equivocal hypodensity in the territory of the right anterior cerebral artery (fig 1). Monitoring of haemostasis showed only moderate fibrinogenolysis (table). During the next days the patient developed a complete paralysis of the left arm and leg and consciousness gradually deteriorated. The CT scan was repeated twice and showed a total anterior cerebral artery infarction with a prominent space occupying effect, a subtotal middle cerebral artery infarction, and a subtotal anterior cerebral artery infarction of the opposite hemisphere (fig 2). After the third CT scan the patient was treated with dexamethasone but to no avail. He died on day 7 after the onset of symptoms. Necropsy was refused.

\section{Discussion}

These findings show that treatment with tissue plasminogen activator started between three and four hours after the onset of symptoms in acute ischaemic stroke may result in excessive ischaemic oedema leading to fatal brain herniation. Though our first patient had bleeding into the subarachnoid space, this could not explain the massive swelling of the right hemisphere. Similar brain swelling was seen in the second patient, who had no bleeding complication. In experiments changes in endothelial permeability were recorded as early as two hours after the ischaemic insult. ${ }^{21}$ It may be that ischaemia for two to five hours causes damage to vessels resulting in leakage rather than haemorrhage and that haemorrhage occurs only after a longer period of ischaemia.

Our study may be criticised for not having used angiography to visualise the embolic occlusion and subsequent dissolution of the cerebral vessels. But this does not change the importance of our finding that fatal brain swelling may occur after treatment with tissue plasminogen activator. If the patients had not had occlusion of cerebral vessels then the fatal effect of thrombolytic treatment would have gone unexplained. Furthermore, if tissue plasminogen activator is to become a standard treatment of stroke its safety and efficacy must be proved in patients with a clinical diagnosis of cerebral infarction. When treatment is to be started within four hours it is not possible to perform pretreatment angiograms. An alternative to angiography might be transcranial Doppler studies. Moreover, an angiogram that does not clearly show the occlusion may be interpreted as indicating that distal migration of the embolic fragments from their initial sites into smaller vessels has occurred. Finally, the complete aphasia in both of our patients and the presence of a large cortical infarction on subsequent CT scans ruled out small vessel disease as the primary ischaemic lesion.

It may be argued that the massive oedema in our patients merely reflected the natural course of large ischaemic strokes and that only a randomised trial will give a definitive answer on this issue. Coning, however, was a rare cause of death in the 56 non-eligible patients with cerebral infarctions of comparable severity; only four died of ischaemic cerebral oedema. The chance that two consecutive patients would have died from coning is therefore $4 / 56 \times 4 / 56=16 / 3136$, or $1 / 196$. It remains to be seen whether very early treatment with tissue plasminogen activator (that is, within two hours), which is being investigated in North America, ${ }^{22}$ is safe.

We thank Mrs Betty Mast for secretarial help. 
1 Barnett HJM. The pathophysiology of transient cerebral ischemic attacks; therapy with platelet antiaggregants. Med Clin North Am 1979;63:649-79

2 Marshall J. The management of cerebrovascular diseases. Oxford: Blackwell Scientific, 1976:57-9.

3 Herndon RII, Nelson JN, Johnson JF, Meyer JS. Thrombolytic treatment in cerebrovascular thrombosis. In: Macmillan RL, Mustard $\mathrm{JF}$, eds. Anticoagulants and fibrinolysis. Philadelphia: Lea and Febiger, 1961:154-64.

4 Mever JS, Herndon RM, Gotoh F, Tazaki Y, Nelson JN, Johnson JF. Therapeutic thrombolysis. In: Millikan $\mathrm{CH}$, Siekert RG, Whisnant Therapeutic thrombolysis. In: Millikan $\mathrm{CH}$, Siekert RG, Whisnant
$\mathrm{JP}$, eds. Cerebral vascular disease. Third Princeton conference. New JP, eds. Cerebral vascular disease. Third
York: Grune and Stratton, 1961:160-77.

5 Mever JS, Gilroy J, Barnhart ME, Johnson JF. Therapeutic thrombolysis in cerebral thromboembolism: randomized evaluation of intravenous streptokinase. In: Millikan CH, Siekert W, Whishant JP, eds. Cerebral I'ascular Diseases. Fourth Princeton conference. New York: Grune and Stratton, 1964:200-13.

6 Fletcher AP, Alkjearsig N, Lewis M, et al. A pilot study of urokinase therapy in cerebral infarction. Stroke 1976;7:135-42.

7 Del Zoppo GJ, Zeumer H, Harker LA. Thrombolytic therapy in stroke. Stroke 1986; 17:595-607.

Sloan MA. Thrombolysis and stroke. Past and future. Arch Neurol 1987;4:748-68

9 Dodson RF, Tagashira Y, Kawamura Y, Wai-Fong Chu L. Morphological responses of cerebral tissues to temporary ischemia. Can $\mathcal{f}$ Veurol Sci 1975:2:173-7.

10 Zeumer H. Survev of progress: vascular recanalizing techniques in interventional neuroradiology. F Neurol 1985;231:287-94.

11 Matsuo $O$, Rijken DC, Collen D. Thrombolysis by human tissue plasminogen activator and urokinase in rabbits with experimental pulmonary embolus. Nature 1981;291:590-1.

12 Collen D, Stassen JM, Verstraete M. Thrombolysis with human extrinsic (tissue-type) plasminogen activator in rabbits with experimental jugular vein thrombosis. Effect of molecular form and dose of activator, age of the thrombus and route of administration. $f$ Clin Invest 1983;71:368-76.

13 TIMI Study Group. The thrombolysis in myocardial infarction (TIMI) trial. Phase I findings. N Engl f Med 1985;312:932-6.

14 Verstraete $M$, Bernard $R$, Bory $M$, et al. Randomized trial of intravenous recombinant tissue-type plasminogen activator versus intravenous streptokinase in acute myocardial infarction: report from the European Cooperative Study Group for Recombinant Tissue-type Plasminogen Activator. Lancet 1985; i:842-7.

15 Verstraete M, Bleifeld W, Brower RW, et al. Double-blind randomized trial of intravenous tissue-type plasminogen activator versus placebo in acute myocardial infarction. Lancet 1985;ii:965-9.

16 Zivin J. Tissue plasminogen activator therapy for embolic stroke. Stroke 986;17:133.

17 Del Zoppo GJ, Copeland BR, Waltz TA, et al. Thrombolytic therapy in a baboon model of acute stroke. Stroke 1986:17(suppl 1):10.

8 Papadopoulos SM, Chandler WF, Salamat MS, Topol EJ, Sackellares JC. Recombinant human tissue-type plasminogen activator therapy in acute thromboembolic stroke. ${ }_{2}$ f Neurosurg 1987;67:394-8.

19 Henze Th, Boeer A, Tebbe U, Romatowski J. Lysis of basilar artery occlusion with tissue plasminogen activator. Lancet 1987;ii:1391.

20 Clauss A. Gerinnungsphysiologische Schnellmethode zur Bestimmung des Fibrinogens. Acta Haematol (Basel) 1957;17:237-46.

21 Petito CK. Early and late mechanisms of increased vascular permeability following experimental cerebral infarction. $\mathcal{F}$ Neuropathol Exp Neurol 1979;38:222-34.

22 Brott T, Haley EC, Levy DE, et al. Very early therapy for cerebral infarction with tissue plasminogen activator [Abstract]. Stroke 1988; infarction

(Accepted 18 October 1988)

\title{
Intravenous methylprednisolone in the treatment of Graves' ophthalmopathy
}

\author{
Pat Kendall-Taylor, Alex L Crombie, Anthea M Stephenson, Mary Hardwick, Keith Hall
}

Departments of Medicine, Ophthalmology, and Human Genetics, University of Newcastle upon Tyne

Pat Kendall-Taylor, MD, professor of endocrinology

Alex L Crombie, FRCSFD, professor of ophthalmology Anthea M Stephenson, BSC, data analyst

Mary Hardwick, MSC, research assistant

\section{Department of}

Neuroradiology,

Newcastle General

Hospital, Newcastle upon

Tyne NE4 6BE

Keith Hall, FRCR, consultant neuroradiologist

Correspondence to:

Professor P Kendall-Taylor,

Ward 10 Office, Roval

Victoria Infirmary,

Newcastle upon Tyne

NE1 4LP.

\section{Abstract}

Eleven euthyroid patients with severe Graves' eye disease were treated with intravenous methylprednisolone and followed up for six months or more by ophthalmological assessment, orbital computed tomography (CT), photographs, and antibody measurements. Papilloedema resolved in the single patient in whom it was present; visual acuity was abnormal in seven eyes initially and in only one eye after treatment; the intraocular pressure differential, which reflects muscle dysfunction, was initially abnormal in 18 eyes but showed a progressive and distinct improvement; nine patients showed substantial improvement in inflammatory signs. Exophthalmos improved early after treatment, but this improvement was not maintained. Orbital CT showed a pronounced reduction in the bulk of eye muscles after treatment in eight of nine patients. Autoantibodies to the thyroid stimulating hormone receptor declined. Adverse effects were trivial. Thus eight patients showed a clear response to intravenous methylprednisolone as judged by ophthalmic assessment and CT scan. The two patients who showed little response and one who had none all had a long history (more than a year) of ophthalmopathy. Results were better than those with oral steroids and adverse effects less.

Treatment of Graves' eye disease is more likely to be effective if given early; patients should be referred promptly to specialist centres, where treatment with intravenous methylprednisolone should be considered.

\section{Introduction}

Graves' ophthalmopathy is a distressing condition which may give rise to diplopia and blindness as well as to unsightly inflammation and proptosis. Treatment of severe ophthalmopathy is not satisfactory. Surgical treatment (orbital decompression) may be employed in centres where it is available, but it is not without complications. Most doctors would prefer medical treatment if possible, and as Graves' ophthalmopathy is almost certainly an autoimmune disease, attempts have been made to suppress the immune response - for example, with steroids, cyclosporin $\mathrm{A}$, or azathioprine - to modulate it by plasma exchange, or to suppress inflammation by orbital irradiation. The most effective of the drugs used for immune suppression are undoubtedly steroids, but to be effective high dosage is necessary, when the frequency and severity of adverse effects are a serious disadvantage. Moreover, the result of steroid treatment with regard to the eyes is usually one of modest improvement rather than reversal of disease.

Large dose bolus intravenous methylprednisolone has been used to good effect in other autoimmune diseases-for example, glomerulonephritis ${ }^{1.3}-$ and we therefore decided to try it in autoimmune ophthalmopathy. As Graves' ophthalmopathy is a nonfatal disease and intravenous methylprednisolone is itself not without risk, we cautiously employed a lower total dose schedule than has been used for either graft rejection or glomerulonephritis. This paper reports on 11 patients treated in this way, who were followed up for six months or more. Measurements were made of different aspects of the disease for statistical assessment and these compared with the changing serum autoantibody activities.

\section{Patients and methods}

The 11 patients (six women, five men) were aged 28 68 years (mean 52.6 ) and had had their eye disease for three to 72 months. Table I gives details of the patients at entry to the study. Only two patients had received any previous immunosuppressive treatment. All were euthyroid at the time treatment was begun and 